\title{
FUSION OF SENTINEL-2 AND PLANETSCOPE IMAGERY FOR VEGETATION DETECTION AND MONITORING
}

\author{
M. Gašparović ${ }^{1, *}$, D. Medak ${ }^{2}$, I. Pilaš ${ }^{3}$, L. Jurjević ${ }^{4}$, I. Balenović $^{5}$ \\ ${ }^{1}$ Chair of Photogrammetry and Remote Sensing, Faculty of Geodesy, University of Zagreb, Kačićeva 26, Zagreb, Croatia - \\ mgasparovic@geof.hr \\ ${ }^{2}$ Chair of Geoinformatics, Faculty of Geodesy, University of Zagreb, Kačićeva 26, Zagreb, Croatia - dmedak@geof.hr \\ ${ }^{3}$ Division for Forest Ecology, Croatian Forest Research Institute, Cvjetno naselje 41, Jastrebarsko, Croatia - ivanp@sumins.hr \\ ${ }^{4}$ Division for Forest Management and Forestry Economics, Croatian Forest Research Institute, Cvjetno naselje 41, Jastrebarsko, \\ Croatia-lukaj@sumins.hr \\ ${ }^{5}$ Division for Forest Management and Forestry Economics, Croatian Forest Research Institute, Cvjetno naselje 41, Jastrebarsko, \\ Croatia - ivanb@sumins.hr
}

Commission I, WG I/8

KEY WORDS: Sentinel-2, PlanetScope, Fusion, Vegetation, Remote Sensing

\begin{abstract}
:
Different spatial resolutions satellite imagery with global almost daily revisit time provide valuable information about the earth surface in a short time. Based on the remote sensing methods satellite imagery can have different applications like environmental development, urban monitoring, etc. For accurate vegetation detection and monitoring, especially in urban areas, spectral characteristics, as well as the spatial resolution of satellite imagery is important. In this research, 10- $\mathrm{m}$ and 20-m Sentinel-2 and 3.7-m PlanetScope satellite imagery were used. Although in nowadays research Sentinel-2 satellite imagery is often used for land-cover classification or vegetation detection and monitoring, we decided to test a fusion of Sentinel-2 imagery with PlanetScope because of its higher spatial resolution. The main goal of this research is a new method for Sentinel-2 and PlanetScope imagery fusion. The fusion method validation was provided based on the land-cover classification accuracy. Three land-cover classifications were made based on the Sentinel-2, PlanetScope and fused imagery. As expected, results show better accuracy for PS and fused imagery than the Sentinel-2 imagery. PlanetScope and fused imagery have almost the same accuracy. For the vegetation monitoring testing, the Normalized Difference Vegetation Index (NDVI) from Sentinel-2 and fused imagery was calculated and mutually compared. In this research, all methods and tests, image fusion and satellite imagery classification were made in the free and open source programs. The method developed and presented in this paper can easily be applied to other sciences, such as urbanism, forestry, agronomy, ecology and geology.
\end{abstract}

\section{INTRODUCTION}

Europe is the highly urbanised continent with a slow but steady degradation of urban vegetation. More than two-thirds of the European population live in urban areas. Naumann et al. (2011) have shown that green infrastructure (GI) is a network of natural and semi-natural areas, features and green spaces in rural and urban areas. GI provides various benefits such as environmental (removal of air pollutants), social (better health and human wellbeing, enhanced tourism and recreation opportunities), adaptation and mitigation to climate change. Today, GI faces harsh growing conditions with heavy traffic patterns and pollution as well as a restriction to water due to increased urbanisation and poor drainage conditions. Konijnendijk et al. (2005) reported that the vitality of urban trees falls drastically during the last $30-40$ years to an average lifespan of a newly planted tree as low as 7-15 years.

Different spatial resolutions satellite imagery with global almost daily revisit time provide valuable information about the earth surface in a short time. Based on the remote sensing methods (e.g. classification, fusion etc.) satellite imagery can have different applications like environmental development (Gašparović et al., 2018c), urban monitoring (Gašparović et al., 2017), forestry management (Hermosilla et al., 2015), hydrology (Donlon et al., 2012 ) etc. For accurate vegetation detection and monitoring, especially in urban areas, spectral characteristics, as well as the spatial and temporal resolution of satellite imagery is important.

Planet, an aerospace company, builds and operates the largest constellation of small imaging satellites PlanetScope (PS), also named Cubesat (Houborg and McCabe, 2018a) or Dove (Asner et al. 2017). Planet operates with more than 175 PlanetScope and collects multispectral (MS) imagery in 4 bands with a spatial resolution of $3.7 \mathrm{~m}$ and a collection capacity of 300 million square $\mathrm{km}$ per day. PS imagery is used for many scientific purposes: McCabe et al. (2017) used PS for vegetation dynamics monitoring; Traganos et al. (2017) used PS for seagrass detection, Gašparović et al. (2018b) used PS for urban vegetation detection and Shi et al. (2018) used PS for mapping damage from rice diseases. Fusion of PS imagery with other satellite data was researched by Houborg and McCabe (2018b) and Kwan et al. (2018).

Gašparović and Jogun (2018) researched the effect of fusing Sentinel-2 (S-2) imagery on land-cover classification accuracy. Previously mentioned authors purpose interesting fusion approach based on the synthesised band calculated by averaging of $10-\mathrm{m}$ bands 4 and 8 . Inspired by research Gašparović and Jogun (2018), a method for fusion of Sentinel-2 and PlanetScope imagery was developed and described in detail below.

* Corresponding author 
The fusion method validation in this research was provided based on the land-cover classification accuracy and compared with land-cover classifications provided separately based on input Sentinel-2, as well as, PlanetScope imagery. All three land-cover classifications were made based on the same supervised classification method, a random forest (RF) classifier. RF is a very popular machine learning algorithm for image classification used in many research as Rodriguez-Galiano et al. (2012), Ahmed et al. (2015) and Gašparović et al. (2018b).

\section{STUDY AREA AND DATA}

This research was provided in the capital city of Croatia, Zagreb. Zagreb is at an elevation of $122 \mathrm{~m}$ above sea level with an area of 641 square $\mathrm{km}$. The city of Zagreb consists of several protected green areas like Medvednica Nature Park, Park Maksimir, as well as a significant number of small parks and recreation zones with developed and cultivated GI like green areas around Jarun lake. For this research central urban, eastern and southern lowland parts of the city were taken into consideration with an area of 125 square $\mathrm{km}(11.2 \mathrm{~km} \times 11.2 \mathrm{~km})$. The study area is surrounded by a Medvednica mountain on the north and river Sava on the south (Figure 1). For easier results representation on a larger scale, the example subset is defined. Example subset is located in surrounding of Jarun lake. In that area are located a lot of cultivated GI with low and high urban vegetation, as well as build-up, water and bare land locations.
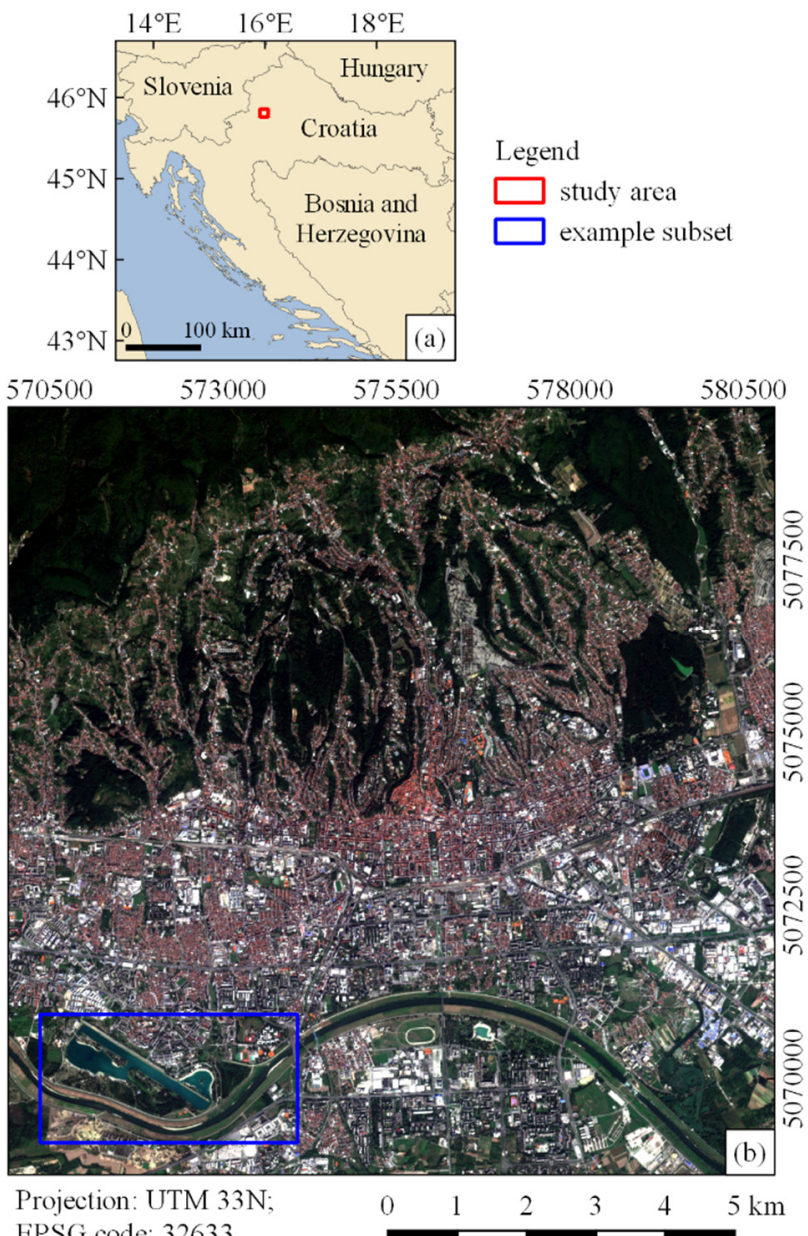

EPSG code: 3263

Figure 1. (a) Location of the study area, (b) study area and

example subset location (S-2 'true colour' composite (4-3-2), sensing date: $13^{\text {th }}$ September 2016)
In this research, $10-\mathrm{m}$ and $20-\mathrm{m}$ Sentinel-2 and 3.7-m PlanetScope satellite imagery were used (Figure 2). Sentinel-2 (S-2) is developed by the European Space Agency specifically for the operational needs of the Copernicus programme. It has an optical multispectral instrument payload that samples 13 spectral bands: four bands at $10 \mathrm{~m}$ spatial resolution, six bands at $20 \mathrm{~m}$ spatial resolution, and three bands at $60 \mathrm{~m}$ spatial resolution. Planet operates with more than 175 PS satellites that collect multispectral imagery in 4 bands with a collection capacity of 300 million square km per day. PS 4-band MS analytic data product - Basic Scene with a spatial resolution of $3.7 \mathrm{~m}$ and for the date $9^{\text {th }}$ September 2016 was used for this research. PS imagery is suitable for the orthorectification, to improve the horizontal accuracy (Gašparović et al., 2018a). For orthorectification of the PS imagery, Shuttle Radar Topography Mission (SRTM) global digital elevation model (GDEM) with a spatial resolution of one arc-second $(\sim 30 \mathrm{~m})$ was used. For this research, we used four 10$\mathrm{m}(2,3,4,8) \mathrm{S}-2$ bands and four 20-m Red Edge (RE; 5, 6, 7, 8a) S-2 bands for the date $13^{\text {th }}$ September 2016.

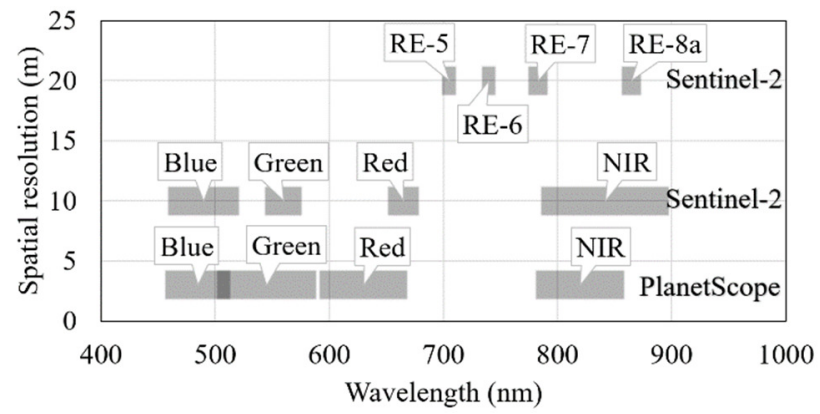

Figure 2. Overview of the Sentinel-2 and PlanetScope spectral bands used in this research

\section{METHODS}

This section explains all the methods used in the research. Figure 3 shows the research workflow.

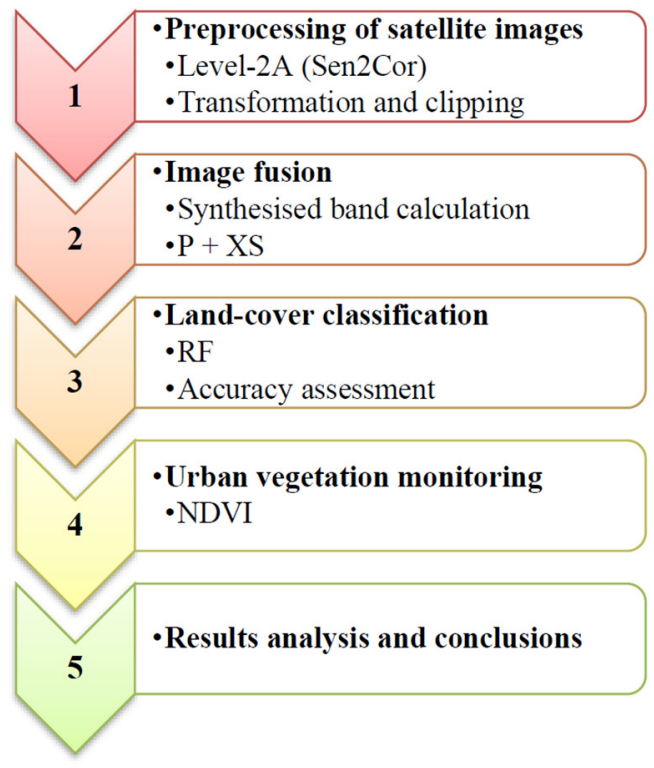

Figure 3. The research workflow 


\subsection{Preprocessing of satellite images}

Preprocessing of Sentinel-2 imagery was performed according to the Level-2A algorithm in Sen2Cor (version 2.2.1) with Sentinel Application Platform (SNAP, version 5.0.0). Because S-2 imagery was georeferenced in the WGS 84 UTM $33 \mathrm{~N}$ coordinate system (EPSG code: 32633), PS imagery was transformed to the same coordinate system, and each band was extracted to separate file. Further, both imagery was clipped to the study area.

\subsection{Image fusion}

Although, in nowadays research Sentinel-2 satellite imagery is often used for land-cover classification or vegetation detection and monitoring in rural, as well as in urban areas, we decided to test a fusion of Sentinel-2 imagery with PS because of its higher spatial resolution. The main goal of this research is development of the new method for Sentinel-2 and PlanetScope imagery fusion. Based on the previous research (Gašparović and Jogun, $2018)$ it is decided to use variational ( $\mathrm{P}+\mathrm{XS}$ ) fusion method. The $\mathrm{P}+\mathrm{XS}$ method introduces the geometry information of the higher resolution image by aligning all edges of the higher resolution image with each lower resolution multispectral band. To obtain the spectral information for the fused image, the method assumes that images taken in different spectral bands share common geometric information and that the higher resolution image can be approximated as a linear combination of the high-resolution multispectral bands (Ballester et al., 2006; He et al., 2012, Gašparović and Jogun, 2018). Based on the previous research (Gašparović and Jogun, 2018), each S-2 band, was fused with a high-resolution PS band with similar spectral characteristics (Figure 2). Therefore, 10-m S-2 bands 2, 3, 4, 8 are fused based on the high-resolution PS bands 1, 2, 3, 4, respectively. Further, 20-m S-2 band 8A are fused based on the PS band 4. Spatial emphasis was given to the fusion problem of $20-\mathrm{m} \mathrm{S}-2$ bands 5 , 6, 7. Accordingly, to Gašparović and Jogun (2018) S-2 bands 5, 6,7 are fused base on the synthesised band (S) given by the equation:

$$
\mathrm{S}=\frac{\mathrm{B}_{3}+\mathrm{B}_{4}}{2},
$$

where $\mathrm{B}_{3}$ and $\mathrm{B}_{4}$ represent PS band 3 and 4 , respectively. Image fusion process of was conducted with the use of open-source software Orfeo ToolBox (OTB) version 6.0.0. OTB algorithm for image fusion was accessed from Monteverdi.

\subsection{Land-cover classification}

The fusion method validation was provided based on the landcover classification accuracy and compared with land-cover classifications provided separately based on input Sentinel-2, as well as PlanetScope imagery. All three land-cover classifications (S-2, PS and fused imagery) were made based on the same supervised classification method, a random forest (RF) classifier. The RF classifier is a combination of tree predictors where each tree depends on the values of a random vector sampled independently from the input vector and with the same distribution for all trees in the forest (Breiman, 2001). Training polygons for the classification were manually selected based on the satellite imagery, randomly and equally for each class. For this research land-cover was divided into five classes (Table 1): water (e.g. lakes, rivers), bare soil (e.g. soil, rocks), built-up (e.g. buildings, roads), forest (e.g. coniferous/non-coniferous forests, shrubs) and low vegetation (e.g. natural grass, crops, pastures).

\begin{tabular}{|l|l|l|}
\hline Class & Class ID & Description \\
\hline Water & 1 & Water bodies \\
Bare soil & 2 & Surfaces without vegetation \\
Built-up & 3 & Human-made constructions \\
Forest & 4 & Wood vegetation \\
Low vegetation & 5 & Annual plants \\
\hline
\end{tabular}

Table 1. Land-cover classes

For supervised classification 150 randomly distributed training polygons were manually collected, which cover almost $0.5 \%$ of the entire study area.

For land-cover classification accuracy assessment, the reference polygons were chosen. Reference polygons are manually selected without spatial overlapping with training polygons. Totally 450 polygons were collected as reference polygons, with a share of a $\sim 0.5 \%$ of the total area of the study area. Accuracy assessment of land-cover classification was calculated based on the confusion matrix. Confusion matrix shows class types determined from reference source in columns, and class types determined from the classified map in rows. Diagonals represent elements classified correctly according to reference data, while off-diagonals were misclassified. Overall accuracy is defined as a sum of the diagonal elements divided by a total number of elements. Besides the overall accuracy, within the confusion matrix, the kappa coefficient can be analysed. The kappa coefficient is a measure of overall statistical agreement of an error matrix, which takes non-diagonal elements into account. Kappa analysis is recognised as a powerful method for comparing the differences between various error matrices (Gašparović et al., 2018b).

\subsection{Urban vegetation monitoring}

For the vegetation monitoring testing, the Normalized Difference Vegetation Index (NDVI) from Sentinel-2 and fused imagery was calculated and mutually compared. This is important for the further research on projects GEMINI (Geospatial monitoring of green infrastructure using terrestrial, airborne and satellite imagery) and 3D-FORINVENT (Retrieval of Information from Different Optical 3D Remote Sensing Sources for Use in Forest Inventory) founded by Croatian Science Foundation, especially for detection and monitoring of urban vegetation as one of the most important factors of life quality in cities. Land-cover classification and urban vegetation monitoring were made in the open source software Quantum GIS (version 2.18.16), GRASS GIS (version 7.2.1) and SAGA GIS (version 6.2.0).

\section{RESULTS}

As mentioned in previous section, three land-cover classifications (S-2, PS and fused imagery) were made based on the same supervised classification method (RF) and same 150 training polygons. For better visual analysis land-cover classification results was shown on $3700 \mathrm{~m} \times 1850 \mathrm{~m}$ example subset located near Jarun lake. Figure 4 shows example subset "true-colour" composite of S-2 and fused imagery. Further, all three land-cover classifications are shown on figure 5. 

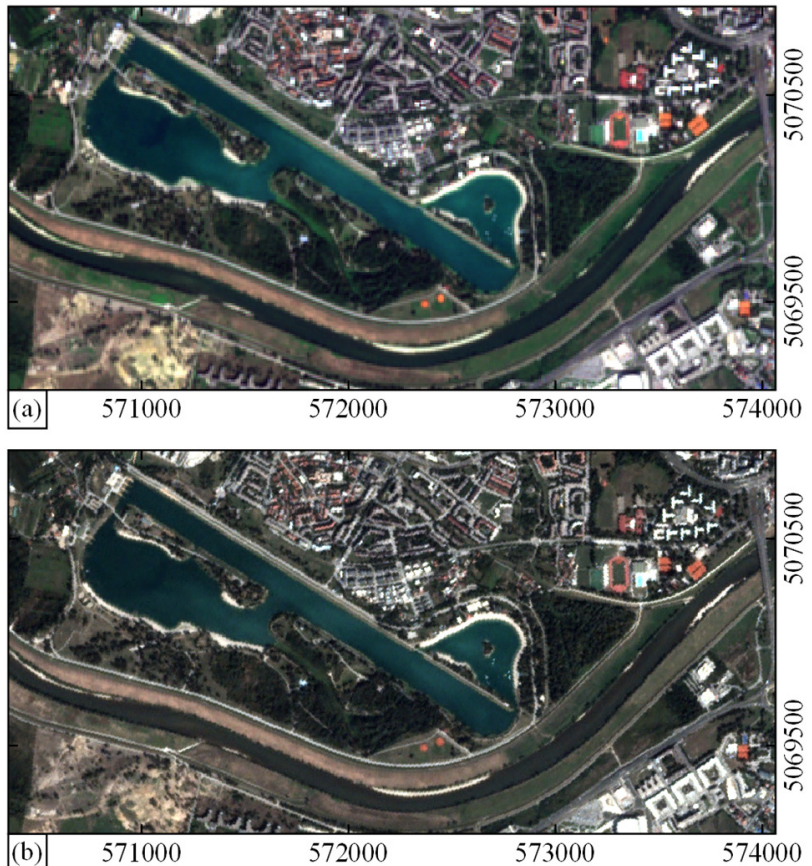

Figure 4. "True-colour" composite of the example subset based on the: (a) S-2 (4-3-2) and (b) fused imagery (3-2-1)
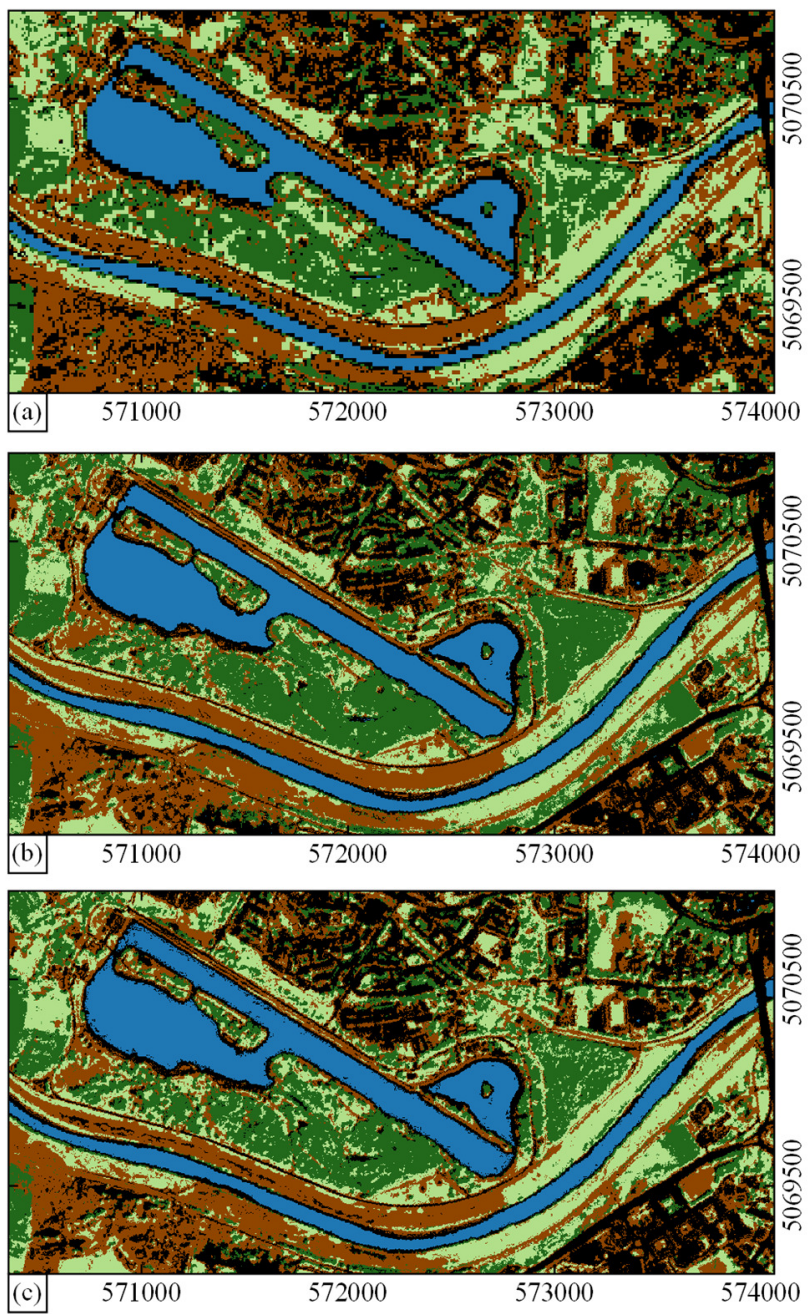

Figure 5. RF classification results of the example subset based on the: (a) S-2, (b) PS and (c) fused imagery
As expected, figure 5 shows huge improvement in land-cover classifications made by PS and fused imagery in comparison to the S-2 imagery. Further, a detailed visual analysis of land-cover classification made base PS, and fused imagery, as well as comparison with satellite imagery with higher spatial resolution (e.g. WorldView-2), was made. From that visual analysis, the boundary of the forest, as well as low vegetation, is better defined by land-cover classification based on the fused imagery than the PS. In the PS-based land-cover classification class forest overemphasised low vegetation in comparison to land-cover classification based on fused imagery. Furthermore, class boundaries in land-cover classification based on the fused imagery are more natural, realistic, and have better coincide with higher spatial resolution satellite imagery than PS based landcover classification.

As an objective quality measurement of the land-cover classifications, accuracy assessment based on the 450 reference polygons was calculated. Table 2, 3 and 4 show confusion matrices, user's and producer's accuracy, kappa coefficient $(\kappa)$, overall accuracy (OA) and the sum of pixels in row and column of confusion matrices $(\Sigma)$ for land-cover classifications. Accuracy assessment was calculated for the entire study area with dimensions $11.2 \mathrm{~km}$ x $11.2 \mathrm{~km}$ (Figure 1).

\begin{tabular}{|c|c|c|c|c|c|c|c|c|c|}
\hline & & \multicolumn{5}{|c|}{ Reference data } & & & \\
\hline \multirow{7}{*}{$\widetilde{\tau}$} & Class ID & 1 & 2 & 3 & 4 & 5 & $\Sigma$ & & \\
\hline & 1 & 4734 & 0 & 6 & 0 & 0 & 4740 & $99.9 \%$ & \multirow{6}{*}{ 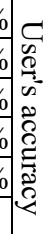 } \\
\hline & 2 & 5 & 946 & 704 & 90 & 1090 & 2835 & $33.4 \%$ & \\
\hline & 3 & 566 & 200 & 3538 & 25 & 89 & 4418 & $80.1 \%$ & \\
\hline & 4 & 77 & 235 & 79 & 9062 & 314 & 9767 & $92.8 \%$ & \\
\hline & 5 & 0 & 684 & 53 & 353 & 3174 & 4264 & $74.4 \%$ & \\
\hline & $\Sigma$ & 5382 & 2065 & 4380 & 9530 & 4667 & 26024 & & \\
\hline & & \multicolumn{5}{|c|}{$88.0 \% 45.8 \%|80.8 \%| 95.1 \% 68.0 \%$} & \multicolumn{3}{|c|}{$\mathrm{OA}=82.44 \%$} \\
\hline & & \multicolumn{5}{|c|}{ Producer's accuracy } & \multicolumn{2}{|c|}{$\kappa=0.77$} & \\
\hline
\end{tabular}

Table 2. Confusion matrix for land-cover classification based on the S-2 imagery

\begin{tabular}{|c|c|c|c|c|c|c|c|c|c|}
\hline & & \multicolumn{5}{|c|}{ Reference data } & & & \\
\hline \multirow{7}{*}{$\bar{U}$} & Class ID & 1 & 2 & 3 & 4 & 5 & $\Sigma$ & & \\
\hline & 1 & 5080 & 0 & 12 & 0 & 1 & 5093 & $99.7 \%$ & $\sigma$ \\
\hline & 2 & 1 & 1270 & 663 & 135 & 667 & 2736 & $46.4 \%$ & $\dddot{\varpi}$ \\
\hline & 3 & 261 & 85 & 3596 & 15 & 177 & 4134 & $87.0 \%$ & $\infty$ \\
\hline & 4 & 39 & 171 & 66 & 9124 & 226 & 9626 & $94.8 \%$ & ڤ్ \\
\hline & 5 & 1 & 539 & 43 & 256 & 3596 & 4435 & $81.1 \%$ & 气 \\
\hline & $\Sigma$ & 5382 & 2065 & 4380 & 9530 & 4667 & 26024 & & \\
\hline & & \multicolumn{5}{|c|}{$94.4 \% 61.5 \%|82.1 \%| 95.7 \% 77.1 \%$} & \multicolumn{3}{|c|}{$\mathrm{OA}=87.10 \%$} \\
\hline & & \multicolumn{5}{|c|}{ Producer's accuracy } & \multicolumn{2}{|c|}{$\kappa=0.83$} & \\
\hline
\end{tabular}

Table 3. Confusion matrix for land-cover classification based on the PS imagery

\begin{tabular}{|c|c|c|c|c|c|c|c|c|c|}
\hline & & \multicolumn{5}{|c|}{ Reference data } & & & \\
\hline \multirow{7}{*}{ 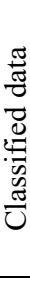 } & Class ID & 1 & 2 & 3 & 4 & 5 & $\Sigma$ & & \\
\hline & 1 & 5037 & 0 & 20 & 0 & 0 & 5057 & $99.6 \%$ & \\
\hline & 2 & 1 & 1208 & 696 & 80 & 330 & 2315 & $52.2 \%$ & \multirow{5}{*}{ 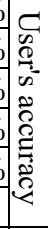 } \\
\hline & 3 & 310 & 107 & 3572 & 38 & 184 & 4211 & $84.8 \%$ & \\
\hline & 4 & 33 & 135 & 44 & 8989 & 93 & 9294 & $96.7 \%$ & \\
\hline & 5 & 1 & 615 & 48 & 423 & 4060 & 5147 & $78.9 \%$ & \\
\hline & $\Sigma$ & 5382 & 2065 & 4380 & 9530 & 4667 & 26024 & & \\
\hline & & \multicolumn{5}{|c|}{ 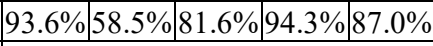 } & \multicolumn{3}{|c|}{$\mathrm{OA}=87.87 \%$} \\
\hline & & \multicolumn{5}{|c|}{ Producer's accuracy } & \multicolumn{2}{|c|}{$\kappa=0.84$} & \\
\hline
\end{tabular}

Table 4. Confusion matrix for land-cover classification based on the fused imagery 
As expected, tables 2, 3, 4 show better accuracy for PS and fused imagery than S-2. If we compare in detail PS and fused imagery it is obvious that overall accuracy (OA) and kappa coefficient $(\kappa)$ are slightly higher for the fused imagery than the PS imagery. Accuracy per classes are also slightly higher for the fused imagery than the PS, but in fact, that is almost negligible.

For our research important information is the area of a particular class. Figure 6 shows the pertinent share of a class in the entire study area based on the three land-cover classifications.

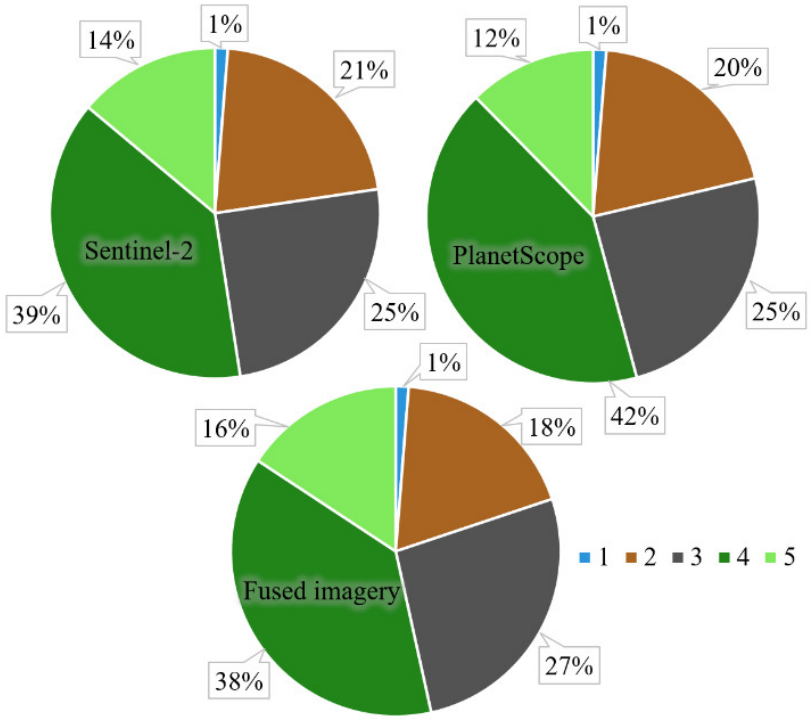

Figure 6. The share of land-cover classes in the entire study area for the classification based on the S-2, PS and fused imagery

For the vegetation monitoring process, NDVI indices for S-2 and fused imagery are calculated. On figure 7 vegetation indices are shown.
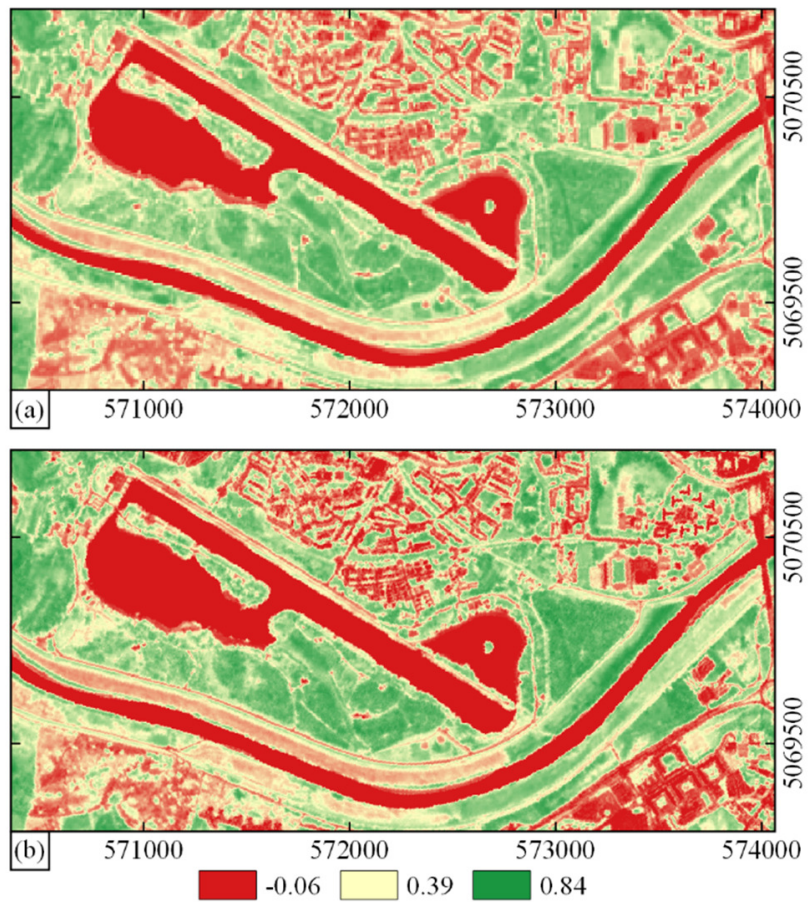

Figure 7. NDVI value of the example subset based on the: (a) S2 and (b) fused imagery
Figure 6 shows that the share of the class in the entire study area based on three independent land-cover classifications are almost equal. As expected, it is possible to see a slight difference between forest and low vegetation in PS and fused imagery. As mentioned before, class forest in PS-based land-cover classification overemphasised low vegetation in comparison to land-cover classification based on fused imagery.

Figure 7 shows that NDVI value S-2 and fused imagery is very similar but in huge difference in spatial and temporal resolution. It should be noted that the S-2 NDVI has 10-m spatial resolution and about 6 days temporal resolution, while the fused imagery we can have almost every day (1-day temporal resolution) and in a $3.7-\mathrm{m}$ spatial resolution.

\section{CONCLUSIONS}

The importance of protected GI areas especially in urban locations are continuously growing. In this research is presented a methodology for vegetation detection and monitoring in an urban location, in Zagreb. The focus of this research is the fusion of Sentinel-2 and PlanetScope satellite imagery. Three landcover classifications were made based on the S-2, PS and fused imagery. As expected, results show better accuracy for landcover classification based on the PS and fused imagery than the S-2 imagery. PS and fused imagery have almost the same accuracy, but it can be seen that fused imagery have slightly higher accuracy than the PS imagery. The share of the class in the entire study area based on three independent land-cover classifications are almost equal. NDVI was used for the vegetation monitoring in this research, and it should be noted that NDVI value for S-2 and fused imagery was very similar. Entire research was provided based on the open source software (SNAP, OTB, GRASS GIS, Quantum GIS, SAGA GIS). The method developed and presented in this paper can easily be applied to other sciences, such as forestry, agronomy, urbanism, ecology and geology.

\section{ACKNOWLEDGEMENTS}

The Croatian Science Foundation has supported this research under the projects GEMINI - Geospatial Monitoring of Green Infrastructure by Means of Terrestrial, Airborne and Satellite Imagery (Grant No. 5621, 2016) and 3D-FORINVENT Retrieval of Information from Different Optical 3D Remote Sensing Sources for Use in Forest Inventory (Grant No. 7686, 2016). PlanetScope imagery is provided through the Planet's Education and Research program.

\section{REFERENCES}

Ahmed, O.S., Franklin, S.E., Wulder, M.A., and White, J.C., 2015. Characterizing stand-level forest canopy cover and height using landsat time series, samples of airborne LiDAR, and the random forest algorithm. ISPRS Journal of Photogrammetry and Remote Sensing, 101, pp. 89-101.

Asner, G.P., Martin, R.E., and Mascaro, J., 2017. Coral reef atoll assessment in the South China Sea using Planet Dove satellites. Remote Sensing in Ecology and Conservation, 3(2), pp. 57-65. Ballester, C., Caselles, V., Igual, L., Verdera, J., and Rougé, B., 2006. A variational model for $\mathrm{P}+\mathrm{XS}$ image fusion. International Journal of Computer Vision, 69(1), pp. 43-58. 
Ballester, C., Caselles, V., Igual, L., Verdera, J., and Rougé, B., 2006. A variational model for $\mathrm{P}+\mathrm{XS}$ image fusion. International Journal of Computer Vision, 69(1), pp. 43-58.

Breiman, L., 2011. Random forests. Machine learning, 45(1), pp $5-32$.

Donlon, C., Berruti, B., Buongiorno, A., Ferreira, M.H., Féménias, P., Frerick, J., Goryl, P., Klein, U., Laur, H., Mavrocordatos, C., and Nieke, J., 2012. The global monitoring for environment and security (GMES) sentinel-3 mission. Remote Sensing of Environment, 120, pp. 37-57.

Gašparović, M., Dobrinić, D., and Medak, D., 2018a. Spatial Accuracy Analysis of Aerial and Satellite Imagery of Zagreb. Geodetski list, 72(1), pp. 1-14.

Gašparović, M., Dobrinić, D., and Medak, D., 2018b. Urban Vegetation Detection Based on the Land-Cover Classification of PlanetScope, RapidEye and WorldView-2 Satellite Imagery. In: 18th International Multidisciplinary Scientific Geoconference SGEM 2018, Vol. 18, Issue 2.3., pp. 249-256.

Gašparović, I., Gašparović, M., and Medak, D., 2018c. Determining and analysing solar irradiation based on freely available data: A case study from Croatia. Environmental Development, 26, pp. 55-67.

Gašparović, M., and Jogun, T., 2018. The effect of fusing Sentinel-2 bands on land-cover classification. International Journal of Remote Sensing, 39(3), pp. 822-841.

Gašparović, M., Zrinjski, M., and Gudelj, M., 2017. Analysis of Urbanization of Split. Geodetski list, 71(3), pp. 189-202.

He, X., Condat, L., Chanussot, J., and Xia, J., 2012. Pansharpening using total variation regularization. Munich, Germany https://doi.org/10.1109/IGARSS.2012.6351611

Hermosilla, T., Wulder, M.A., White, J.C., Coops, N.C., and Hobart, G.W., 2015. Regional detection, characterization, and attribution of annual forest change from 1984 to 2012 using Landsat-derived time-series metrics. Remote Sensing of Environment, 170, pp. 121-132.

Houborg, R., and McCabe, M.F., 2018a. A Cubesat enabled Spatio-Temporal Enhancement Method (CESTEM) utilizing Planet, Landsat and MODIS data. Remote Sensing of Environment, 209, pp. 211-226.

Houborg, R., and McCabe, M.F., 2018b. Daily Retrieval of NDVI and LAI at $3 \mathrm{~m}$ Resolution via the Fusion of CubeSat, Landsat, and MODIS Data. Remote Sensing, 10(6), 890.

Konijnendijk C.C., Nilsson K, Randrup T.B., and Schipperijn J., 2005. Urban forests and trees: a reference book, Springer Science \& Business Media, Berlin, pp. 1-520.

Kwan, C., Zhu, X., Gao, F., Chou, B., Perez, D., Li, J., Shen, Y., Koperski, K., and Marchisio, G., 2018. Assessment of Spatiotemporal Fusion Algorithms for Planet and Worldview Images. Sensors, 18(4), 1051.

McCabe, M. F., Aragon, B., Houborg, R., and Mascaro, J., 2017. CubeSats in Hydrology: Ultrahigh-Resolution Insights Into Vegetation Dynamics and Terrestrial Evaporation. Water Resources Research, 53(12), pp. 10017-10024.
Naumann, S., Davis, M., Kaphengst, T., Pieterse, and M., Rayment, M., 2011. Design, implementation and cost elements of Green Infrastructure projects, Final report, European Commission, Brussels, pp. 1-138.

Rodriguez-Galiano, V.F., Ghimire, B., Rogan, J., Chica-Olmo, M., and Rigol-Sanchez, J.P., 2012. An assessment of the effectiveness of a random forest classifier for land-cover classification. ISPRS Journal of Photogrammetry and Remote Sensing, 67, pp. 93-104.

Shi, Y., Huang, W., Ye, H., Ruan, C., Xing, N., Geng, Y., Dong, Y., and Peng, D., 2018. Partial Least Square Discriminant Analysis Based on Normalized Two-Stage Vegetation Indices for Mapping Damage from Rice Diseases Using PlanetScope Datasets. Sensors, 18(6), 1901.

Traganos, D., Cerra, D., and Reinartz, P., 2017. CubeSat-derived detection of seagrasses using Planet imagery following Unmixing-based Denoising: is small the next big? In: The International Archives of the Photogrammetry, Remote Sensing and Spatial Information Sciences, Vol. XLII-1/W1, pp. 283- 287.

Revised July 2018 